\title{
ASSESSMENT OF ZINC OXIDE, CALCIUM HYDROXIDE, AND SODIUM FLUORIDE MIX VERSUS ZINC OXIDE EUGENOL MIX AS OBTURAT- ING MATERIALS IN DECIDUOUS TEETH (CLINICAL AND RADIO- GRAPHIC STUDY)
}

\author{
Mohammed. T ${ }^{1}$, Baiomy. S.Y ${ }^{2}$, Barakat. I ${ }^{3}$
}

\begin{abstract}
Objectives: This study compared the clinical and radiographic effects of two medicaments. Subjects and Methods: Endodontic treatment was performed on 26 pulpally involved primary molars in 4 to 7 years old children suffering from badly decayed or carious primary teeth which indicated for root canal treatment. Two medicaments (3Mix and ZOE) on the pulpectomized teeth comprised 2 main groups. The root canals were obturated with zinc oxide eugenol mix in the first group and a mixture of calcium hydroxide, zinc oxide, and $10 \%$ sodium fluoride solution in the second group , using hand-operated lentulo-spirals. The teeth were evaluated clinically and radiographically at different intervals ( 3 months, 6 months, 12 months). Results: In the first group, pulpectomy with zinc oxide eugenol gave raise a $92.3 \%$ success rate, while the second group with triple antibiotic paste was $84.6 \%$. Conclusion: Shows that $\mathrm{ZnOE}$ offers good clinical and radiographical results when compared with Tiple mix paste but with no statistically significant differences.
\end{abstract}

KEYWORDS: Triple mix, ZOE, pulpectomy.

\section{INTRODUCTION}

Ideal pulpectomy obturation materials should be antimicrobial. Since obturation materials can exit the apex and distribute locally and systemically, they need to be biocompatible. They also should be resorbable at speeds close to the physiologic root resorption $^{(1)}$.

The most common obturation materials in primary teeth are zinc oxide eugenol (ZOE) and compounds of iodoform and calcium hydroxide $(\mathrm{Ca}(\mathrm{OH}) 2)$. $\mathrm{ZnOE}$ has a slow rate of resorption and has a tendency to be retained even after tooth exfoliation; in some cases, unresorbed material has been found to cause deflection of the succedaneous tooth. $\mathrm{ZnOE}$ has also been used in combination with different fixative agents, formaldehyde, formocresol, paraformaldehyde, and cresol, all of which have inherent cytotoxicity apart from other drawbacks ${ }^{(2)}$.

Zinc oxide-eugenol (ZOE) has been the material of choice for many years. Although this agent showed antibacterial effects against pure cultures of bacteria in several studies combining

1. Demonstrator, Pedodontic and Oral Health Department, Faculty of Dentistry, Al Azhar University

2. Professor, Pedodontic and Oral Health Department, Faculty of Dentistry, Al Azhar University.

3. Assistant Professor, Pedodontic and Oral Health Department Faculty of Dentistry, Al Azhar University

-Corresponding author: tarekdent13685@gmail.com 
with formocresol increased its antibacterial effect. Another material, Kri paste, a mixture of iodoform, camphor, p-chlorophenol, and menthol also exerts a strong antimicrobial effect in vitro, A third material, Vitapex, a mixture ofiodoform and calciumhydroxide $[\mathrm{Ca}(\mathrm{OH}) 2]$ demonstrated inhibitory activity against Streptococcus mutans, Staphylococcus aureus, and Lactobacillus casei. Cox et al. found that zinc oxide alone could not inhibit Escherichia coli, S. aureus, or Streptococcus viridans, but ZOE inhibited S. aureus and S.viridans ${ }^{(3)}$.

Calcium hydroxide is another useful pulpectomy root filling material with success rates of about $88 \%$. However, these materials have their limitations, and there is room for the introduction of other antimicrobial agents with similar or better biocompatibility. For instance, both KRI and ZOE are cytotoxic; the cytotoxicity of KRI remains for 7 days after its setting, while the cytotoxicity of $\mathrm{ZOE}$ reaches the baseline after one day ${ }^{(4)}$.

To overcome the disadvantages of $\mathrm{ZnOE}$, calcium hydroxide, and iodoform, and their different formulations, use of a mixture of zinc oxide powder and calcium hydroxide as a root canal filling material in primary molars. This mixture was also reported to resorb earlier than the physiologic resorption of the roots of the primary teeth if the root canal filling material contained fluoride, it would leach out fluoride, which could be beneficial to the erupting tooth. Also, there was the possibility that the combination of zinc oxide powder and calcium hydroxide might form a mixture that would delay resorption ${ }^{(5)}$.

\section{SUBJECTS AND METHODS}

\section{Ethical consideration}

The research protocol will be approved by the Ethical Committee of Faculty of Dental Medicine, Boys, Cairo, Al - Azhar University. Also, the parent of each child enrolled in the study will sign an informed written consent form.
This study performed on 26 primary molars from 20 children their ages ranged from (4-7) years suffering from badly decayed or carious primary teeth which indicated for root canal treatment. The children were classified into two equal groups; each group comprised of (13) primary molars teeth.

\section{GROUPA}

This group $(\mathrm{n}=13)$

The primary molars of this group were received root canal treatment with zinc oxide eugenol.

\section{GROUP B}

This group $(\mathrm{n}=13)$

The primary molars of this group were received root canal treatment with zinc oxide, calcium hydroxide, sodium fluoride mix.

Inclusion criteria: An age range from (3-6) year; patient and parent cooperation; absence of any systemic disease which would contraindicate pulp therapy; presence of clinical signs or symptoms suggesting non-vital primary molar indicated for partial pulpectomy; and the possibility for establishing a final restoration of the tooth.

Exclusion criteria: Apical or internal resorption; furcation involvement; physiologic root resorption (more than 1/3 of the roots resorbed); unrestorable teeth; and uncooperative child.

The root canal treatment in each case was carried out under a rubber dam after administration of local anaesthesia using Mepecaine-L (a local anaesthetic solution containing 20mg Mepivacaine hydrochloride with $0.06 \mathrm{mg}$ Levonordefrin hydrochloride) used by a single block injection. The procedure involved cavity preparation, removal of all carious tooth structure, making straight-line access, and extirpation of pulpal debris from the root canals using files, and copious irrigation with $2.5 \%$ sodium 
hypochlorite. After establishing the working length, the canals were prepared with ProTaper rotary files(Dentsply Maillefer, Ballaigues, Switzerland), $\mathrm{SX}(19 \mathrm{~mm}), \mathrm{S} 1(25 \mathrm{~mm})$ and $\mathrm{S} 2(25 \mathrm{~mm})$.

The root canals were filled using the mixture made out of calcium hydroxide paste and zinc oxide powder, with $10 \%$ sodium fluoride solution as the liquid and other group filled with zinc oxide eugenol paste. Hand lentulo spiral was used with a clockwise rotatory motion to fill the material into the root canals. The teeth were clinically and radiographically evaluated regularly after 3 months, 6 months and 12 months or till the exfoliation of the teeth. At each follow-up visit, the teeth were assessed clinically for pain, tenderness on percussion, and mobility.

The criteria for success were based on clinical and radiographic evidence:

1. No history of pain or discomfort.

2. No swelling.

3. No mobility.

4. No fistula.

5. No apical or bifurcation radiolucent areas.

The collected data were tabulated and analyzed statistically using Statistical Package for Social Science (SPSS) program version 20.0.

\section{RESULTS}

According to radiolucency in the first group, pulpectomy with zinc oxide eugenol gave raise a 92.3\% success rate, while the second group with triple antibiotic paste was $84.6 \%$. (Tab.1, Fig.1)

According to pain for (ZOE) group; 1 (7.7\%) cases showed positive result while 12 (92.3\%) showed negative result, (Triple mix) group; $2(15.4 \%)$ cases showed positive result while11 (84.6\%) showed the negative results. (Tab.2, Fig.2)
TABLE (1): Comparison between the two studied groups according to radiolucency at 12 months

\begin{tabular}{|c|c|c|c|}
\hline \multirow{2}{*}{$\begin{array}{l}\text { Radiolucency } \\
\text { at } 12 \text { months }\end{array}$} & \multicolumn{2}{|c|}{ Procedure } & \multirow[b]{2}{*}{ Total } \\
\hline & $\begin{array}{c}\text { Zinc oxide } \\
\text { eugenol }\end{array}$ & Triple mix & \\
\hline \multicolumn{4}{|l|}{ Negative } \\
\hline$-\quad \mathrm{N}$ & 12 & 11 & 23 \\
\hline$-\quad \%$ & $92.3 \%$ & $84.6 \%$ & $88.5 \%$ \\
\hline \multicolumn{4}{|l|}{ Positive } \\
\hline$-\quad \mathrm{N}$ & 1 & 2 & 3 \\
\hline$-\quad \%$ & $7.7 \%$ & $15.4 \%$ & $11.5 \%$ \\
\hline \multicolumn{4}{|l|}{ Total } \\
\hline$-\quad \mathrm{N}$ & 13 & 13 & 26 \\
\hline$-\quad \%$ & $100 \%$ & $100 \%$ & $100 \%$ \\
\hline $\begin{array}{c}\text { Test of } \\
\text { significance }\end{array}$ & & $\begin{array}{l}{ }^{2}(\mathrm{df}=1)=0.37 \\
\mathrm{p}=0.539 \mathrm{NS}\end{array}$ & \\
\hline
\end{tabular}

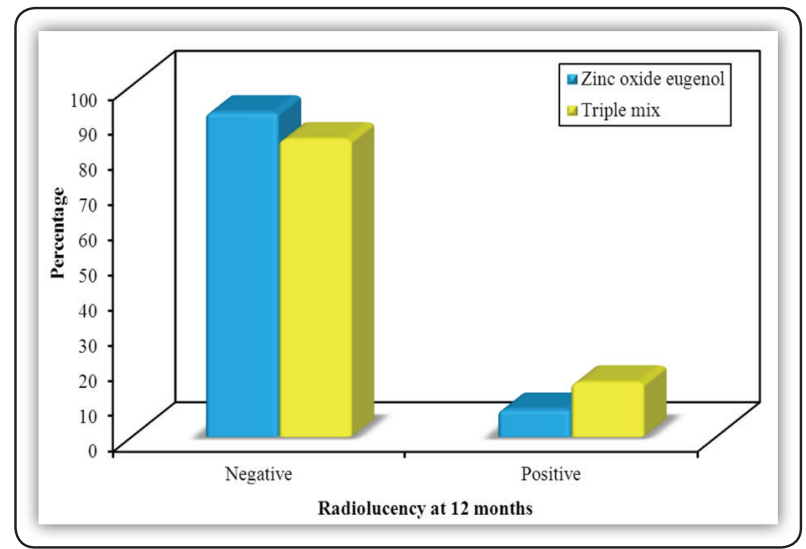

FIG (1) Comparison between the two studied groups according to radiolucency at 12 months

TABLE (2): Comparison between the two studied groups according to pain

\begin{tabular}{|c|c|c|c|c|c|}
\hline \multirow[t]{2}{*}{ Pain } & \multicolumn{2}{|c|}{$\begin{array}{c}\text { ZOE } \\
(n=13)\end{array}$} & \multicolumn{2}{|c|}{$\begin{array}{l}\text { TRIPLE } \\
(\mathrm{n}=13)\end{array}$} & \multirow[t]{2}{*}{$\mathbf{P}$} \\
\hline & No. & $\%$ & No. & $\%$ & \\
\hline \multicolumn{6}{|l|}{3 months } \\
\hline Negative & 13 & 100.0 & 13 & 100.0 & \multirow{2}{*}{1.000} \\
\hline Positive & 0 & 0.0 & 0 & 0.0 & \\
\hline \multicolumn{6}{|l|}{6 months } \\
\hline Negative & 12 & 92.3 & 10 & 76.9 & \multirow{2}{*}{$\begin{array}{c}{ }^{\mathrm{FE}} \mathrm{p}= \\
0.593\end{array}$} \\
\hline Positive & 1 & 7.7 & 3 & 23.1 & \\
\hline \multicolumn{6}{|l|}{12 months } \\
\hline Negative & 12 & 92.3 & 11 & 84.6 & ${ }^{\mathrm{FE}} \mathrm{p}=$ \\
\hline Positive & 1 & 7.7 & 2 & 15.4 & 1.000 \\
\hline $\mathbf{Q}$ & \multicolumn{2}{|c|}{2.000} & \multicolumn{2}{|c|}{4.667} & \\
\hline $\mathrm{p}_{0}$ & \multicolumn{2}{|c|}{0.368} & \multicolumn{2}{|c|}{0.097} & \\
\hline
\end{tabular}




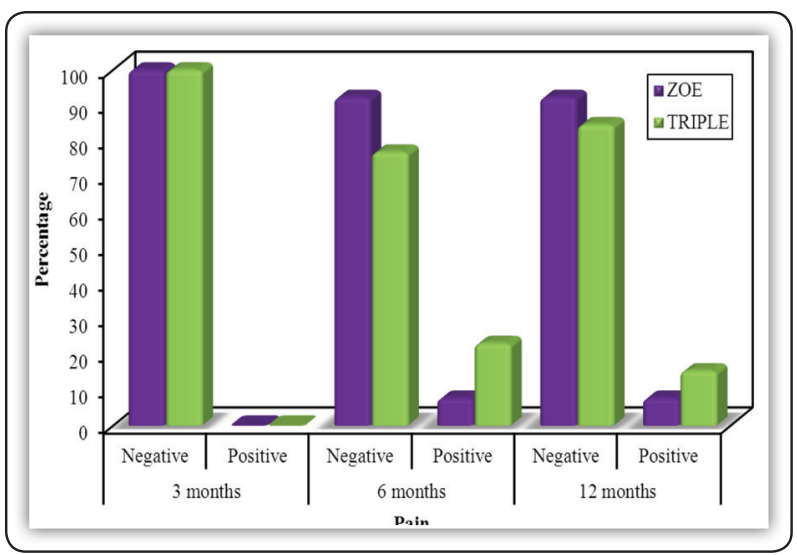

FIG (2) Comparison between the three studied periods according to pain in both group.

According to swelling for (ZOE) group; 1 $(7.7 \%)$ cases showed positive result while12 (92.3\%) showed negative result, (Triple mix) group; $2(15.4 \%)$ cases showed positive result while 11 (84.6\%) showed the negative results. (Tab3, Fig.3)

According to mobility for (ZOE) group; 1 (7.7\%) case showed positive result while $12(92.3 \%)$ showed negative result, (Triple mix) group; 2 (15.4\%) cases showed positive result while $11(84.6 \%)$ showed the negative result. (Tab.4, Fig.4)

TABLE (3): Comparison between the two groups according to swelling

\begin{tabular}{|c|c|c|c|c|c|}
\hline \multirow[t]{2}{*}{ Swelling } & \multicolumn{2}{|c|}{$\begin{array}{c}\text { ZOE } \\
(n=13)\end{array}$} & \multicolumn{2}{|c|}{$\begin{array}{l}\text { TRIPLE } \\
(\mathrm{n}=13)\end{array}$} & \multirow[t]{2}{*}{${ }^{\mathrm{FE}} \mathbf{p}$} \\
\hline & No. & $\%$ & No. & $\%$ & \\
\hline \multicolumn{6}{|l|}{3 months } \\
\hline Negative & 13 & 100.0 & 12 & 92.3 & \multirow{2}{*}{1.000} \\
\hline Positive & 0 & 0.0 & 1 & 7.7 & \\
\hline \multicolumn{6}{|l|}{6 months } \\
\hline Negative & 12 & 92.3 & 11 & 84.6 & \multirow{2}{*}{1.000} \\
\hline Positive & 1 & 7.7 & 2 & 15.4 & \\
\hline \multicolumn{6}{|l|}{12 months } \\
\hline Negative & 12 & 92.3 & 11 & 84.6 & \multirow{2}{*}{1.000} \\
\hline Positive & 1 & 7.7 & 2 & 15.4 & \\
\hline $\mathbf{Q}$ & \multicolumn{2}{|c|}{2.000} & \multicolumn{2}{|c|}{2.000} & \\
\hline $\mathrm{p}_{0}$ & \multicolumn{2}{|c|}{0.368} & \multicolumn{2}{|c|}{0.368} & \\
\hline
\end{tabular}

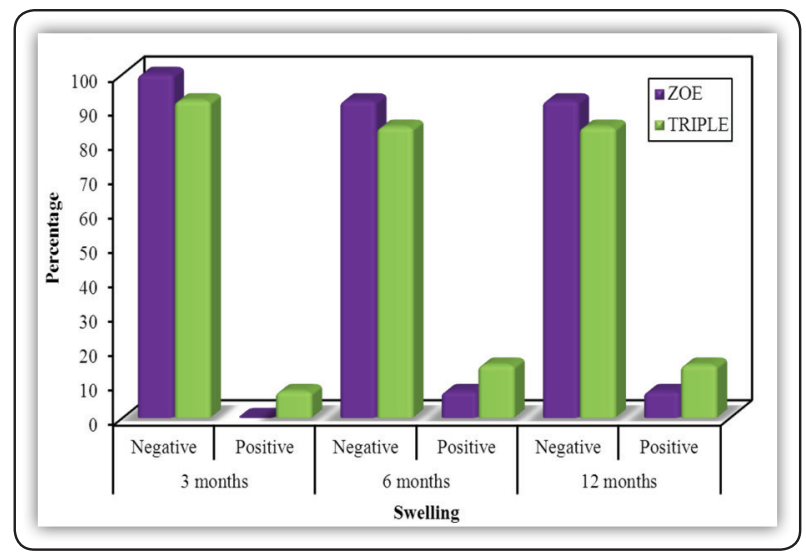

FIG (3) Comparison between the three studied periods according to swelling in both group.

TABLE (4): Comparison between the two groups according to mobility

\begin{tabular}{|c|c|c|c|c|c|}
\hline \multirow[t]{2}{*}{ Mobility } & \multicolumn{2}{|c|}{$\begin{array}{c}\text { ZOE } \\
(n=13)\end{array}$} & \multicolumn{2}{|c|}{$\begin{array}{l}\text { TRIPLE } \\
(n=13)\end{array}$} & \multirow[t]{2}{*}{${ }^{\mathrm{FE}} \mathbf{p}$} \\
\hline & No. & $\%$ & No. & $\%$ & \\
\hline \multicolumn{6}{|l|}{3 months } \\
\hline Negative & 11 & 84.6 & 11 & 84.6 & \multirow{2}{*}{1.000} \\
\hline Positive & 2 & 15.4 & 2 & 15.4 & \\
\hline \multicolumn{6}{|l|}{6 months } \\
\hline Negative & 12 & 92.3 & 12 & 92.3 & \multirow{2}{*}{1.000} \\
\hline Positive & 1 & 7.7 & 1 & 7.7 & \\
\hline \multicolumn{6}{|l|}{12 months } \\
\hline Negative & 12 & 92.3 & 11 & 84.6 & \multirow{2}{*}{1.000} \\
\hline Positive & 1 & 7.7 & 2 & 15.4 & \\
\hline $\mathbf{Q}$ & \multicolumn{2}{|c|}{2.000} & \multicolumn{2}{|c|}{2.000} & \\
\hline $\mathrm{p}_{0}$ & \multicolumn{2}{|c|}{0.368} & \multicolumn{2}{|c|}{0.368} & \\
\hline
\end{tabular}

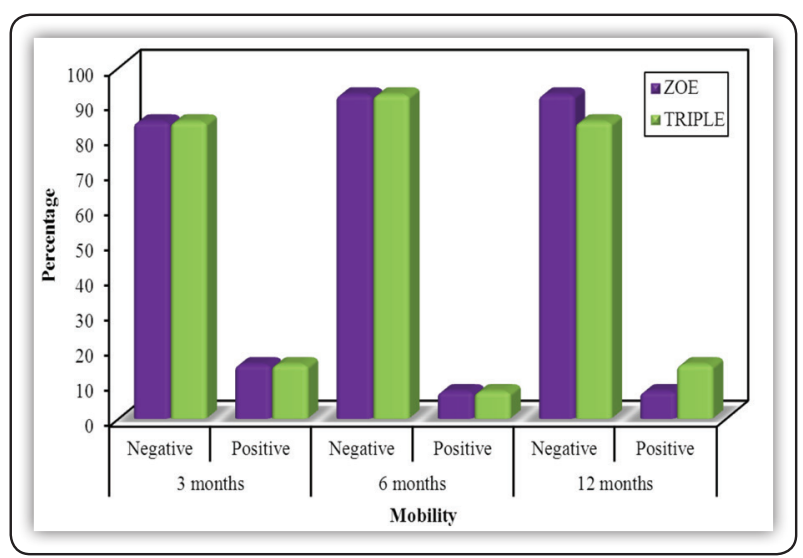

FIG (4) Comparison between the three studied periods according to mobility in both group. 
According to fistula for both groups; 1 case (7.7\%) showed positive result while12 (92.3\%) showed the negative result. (Tab.5, Fig.5)

TABLE(5) Comparison between the two groups according to fistula

\begin{tabular}{|c|c|c|c|c|c|}
\hline \multirow{2}{*}{ Fistula } & \multicolumn{2}{|c|}{$\begin{array}{c}\text { ZOE } \\
(n=13)\end{array}$} & \multicolumn{2}{|c|}{$\begin{array}{c}\text { TRIPLE } \\
(n=13)\end{array}$} & \multirow[t]{2}{*}{$\mathbf{P}$} \\
\hline & No. & $\%$ & No. & $\%$ & \\
\hline \multicolumn{6}{|l|}{3 months } \\
\hline Negative & 13 & 100.0 & 13 & 100.0 & \multirow{2}{*}{1.000} \\
\hline Positive & 0 & 0.0 & 0 & 0.0 & \\
\hline \multicolumn{6}{|l|}{6 months } \\
\hline Negative & 12 & 92.3 & 12 & 92.3 & \multirow{2}{*}{$\begin{array}{l}{ }^{\mathrm{FE}} \mathrm{p}= \\
1.000\end{array}$} \\
\hline Positive & 1 & 7.7 & 1 & 7.7 & \\
\hline \multicolumn{6}{|l|}{12 months } \\
\hline Negative & 12 & 92.3 & 12 & 92.3 & \multirow{2}{*}{$\begin{array}{l}{ }^{\mathrm{FE}} \mathrm{p}= \\
1.000\end{array}$} \\
\hline Positive & 1 & 7.7 & 1 & 7.7 & \\
\hline $\mathbf{Q}$ & \multicolumn{2}{|c|}{2.000} & \multicolumn{2}{|c|}{2.000} & \\
\hline $\mathrm{p}_{0}$ & \multicolumn{2}{|c|}{0.368} & \multicolumn{2}{|c|}{0.368} & \\
\hline
\end{tabular}

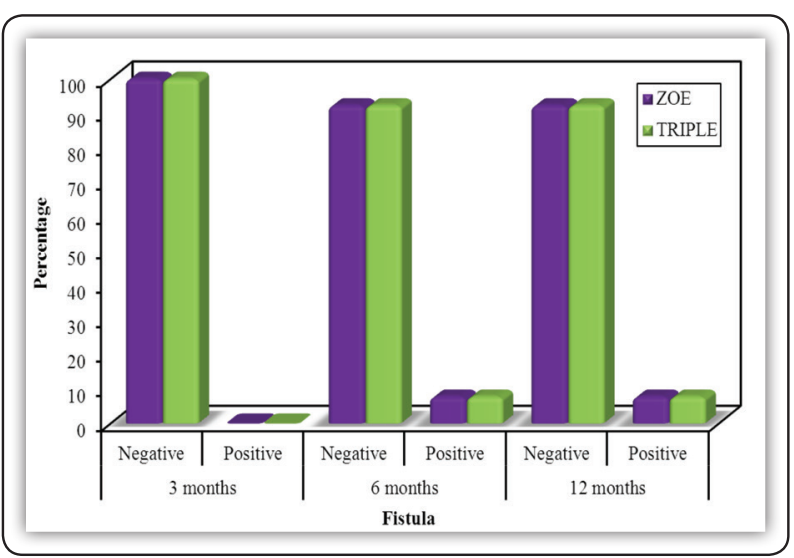

FIG (5) Comparison between the three periods according to fistula in both group.

\section{DISCUSSION}

On regard to the positive response observed in group A, the success rate was approximately $(92.3 \%)$ since 12 teeth from 13 showed no signs and symptoms of inflammation clinically. Moreover, the absence of periapical and furcation radiolucency, root resorption and swelling. This result was in agreement with Barcelos ${ }^{(6)}$, who recorded (85$100 \%)$ success rate, also with Subramaniam \& Gilhotra, who recorded ( 93.3\%) success rate ${ }^{(7)}$.

Moreover, Arvind, who recorded (100\%) success rate of ZOE pulpectomy. The high clinical and radiographic success rate of Group $\mathrm{A}$ in this study may attributable to ZOE produced better antimicrobial activity and produced a greater zone of bacterial inhibition. Also produce healthy tissue (absence of swelling, redness or sinus tract) absence of pain, or abnormal mobility, Continuity of lamina dura, reduction in the size of any pathologic interradicular or periapical radiolucencies and evidence of bony regeneration ${ }^{(8)}$.

Generally, these study results are in agreement with other investigators ${ }^{(9)}$, who recorded $(65 \%)$ success rate, this success differences may be related to the pathologic condition of the tooth before treatment rather than to the filling technique. Also, other searchers ${ }^{(10)}$, who report $(77 \%)$ success rate also other studies report (60\%) success rate of $\mathrm{ZOE}$ pulpectomy ${ }^{(11)}$.

Otherwise Nivedita Rewal, Arun Singh Thakur noted the zinc oxide eugenol does not meet all criteria required for an ideal root canal filling material. They reported delayed resorption of extruded material, deflected or ectopic eruption of the succedaneous tooth, anterior crossbite, and palatal eruption following zinc oxide eugenol pulpectomy. Also, zinc oxide eugenol is a periapical irritant and utmost care should be taken not to force material past the apex and has limited antibacterial activity ${ }^{(12)}$.

On regard to the positive response observed in group $\mathrm{B}$, the success rate was approximately $(84.6 \%)$ since 11 teeth from 13 showed no signs and symptoms of inflammation clinically. This result was in agreement with Chawla HS and Setia $\mathrm{S}$, who recorded (88\%) success rate and this high success rate could be attributed to the root canal material from within the canal (intraradicularly) resorbed along with the resorption of the roots ${ }^{(13)}$. 
Moreover, DV Divya and Madu Ghanashyam Prasad, reported $93 \%$ success rate may be referred to 3Mix can be considered as an effective root canal filling material in primary teeth due to its healing ability, bone regeneration characteristics, and its resorption of excess material without washing within the roots ${ }^{(14)}$. Also, Qadeer and Sadaf have recorded a $90 \%$ success rate as 3 MIX is significantly more effective in the treatment of pulpally involved primary molars as compared to Vitapex ${ }^{(15)}$. Rishi Nanda and Monika Koul, reported an 81\% success rate as 3 Mix antibacterial pastes can be used effectively in non-instrumental endodontic treatment of necrosed primary teeth ${ }^{(16)}$

Also, other studies reported an $82.7 \%$ success rate may be due to $3 \mathrm{Mix}$ has shown good clinical success but a low success rate in radiographic evaluation. And indication for the use of $3 \mathrm{Mix}$ therapy is when there is external root resorption and endodontic treatment cannot be rendered. Another indication for the use of 3Mix therapy is in cases where the tortuousness of the tooth roots makes them less amenable to biomechanical preparation ${ }^{(17)}$.

Moreover, other investigators reported $95.1 \%$ success rate as 3 MIX has radiographic success was taken as the combination of a decrease in furcation radiolucency, resorption of material within the root canal and complete resorption of excess filling material and have the advantage of resorption limited to the excess extruded extraradicularly; without washing out intraradicularly ${ }^{(18)}$.

In the present study, the radiographic investigation revealed an improvement, at the end of the follow-up period (12 months) with both ZOE and Triple mix treated teeth. This finding agrees with other studies ${ }^{(8,13,14,15,16)}$ since clinical and radiographic results revealed success at the aforementioned intervals. However, ZOE proved promising better healing ability and positive responses than Triple mix in pulpotomies.

\section{CONCLUSION}

Based on the study finding it could be concluded that $\mathrm{ZnOE}$ offers good clinical and radiographical results when compared with Tiple mix paste but with no statistically significant differences.

\section{REFERENCE}

1. Fuks AB, Kupietsky A, Guelmann M. Pulp therapy for the primary dentition. Pediatric Dentistry,2013; 333-51.

2. Mani SA, Chawla HS, Tewari A, Goyal A. evaluation of calcium hydroxide and zinc oxide as a root canal filling material in primary teeth. ASDC J Dent Child, 2000; 67:142-7.

3. Seow WK.The effects of dyadic combinations of endodontic medicaments on microbial growth inhibition. Pediatr Dent, 1990;12:292-97.

4. Nurko C, Garcia-Godoy F.Evaluation of a calcium hydroxide /iodoform paste (Vitapex) in root canal therapy for primary teeth. J Clin Pediatr Dent, 1999;23(4): 289-94.

5. Chawla HS, Mathur VP, Gauba K, Goyal A. A mixture of calcium hydroxide paste and zinc oxide as a root canal filling material for primary teeth: A preliminary study. J Indian Soc Pedo Prev Dent,2001;19:107-9.

6. Barcelos R, Santos MP, Primo LG, Luiz RR, Maia LC. ZOE paste pulpectomies outcome in primary teeth: a systematic review. J Clin Pediatr Dent, 2011: 35: 241-8.

7. Subramaniam P, Gilhotra K. Endoflas, zinc oxide eugenol and metapex as root canal filling materials in primary molars: a comparative clinical study. J Clin Pediatric Dent, 2011; 35: 365-9. Pediatr Dent 2011: 35: 365-369

8. Arvind K. A comparison of zinc oxide-eugenol with Endoflas F.S. as root canal sealer in single-visit endodontic therapy. J Dent Res \& Therapy, 2009; 1: 1-3.

9. Holan G, Fuks AB. A comparison of pulpectomies using ZOE and KRI paste in primary molars: a retrospective study. Pediatr Dent 1993; 15: 403-7.

10. James A. Coil, Roya Sadrian. Predicting pulpectomy success and its relationship to exfoliation and succedaneous dentition. 1996; 18:1.

11. Reddy VV, Fernandes A. Clinical and radiological evaluation of zinc oxide-eugenol and Maisto's paste as obturating materials in infected primary teeth. J Indian Soc Pedod Prev Dent,1996; 14: 39-44. 
12. Coll JA, Sadrian R. Predicting pulpectomy success and its relationship to exfoliation and succedaneous dentition. Pediatr Dent, 1996; 18:57-63.

13. Chawla HS, Setia S, Gupta N, Gauba K, Goyal A. Evaluation of a mixture of zinc oxide, calcium hydroxide, and sodium fluoride as a new root canal filling material for primary teeth. J Indian Soc Pedod Prev Dent, 2008; 26: 53-8.

14. DV Divya, Madu Ghanashyam Prasad. Triple antibiotic paste versus propolis: A clinical quest for the reliable treatment of periapical lesions in primary molars. J Indian Soc Pedod Prev Dent ,2019; 9(1) :34-9.

15. QADEER, SADAF; MUNIR. Comparison of the effectiveness of Triple antibiotic paste (3mix) and vtapex for root canal treatment of pulpally involved primary molars. Pakistan Oral \& Dental Journal, 2016; 36: 654-7.

16. Rishi N, Monika K, Salil S. Clinical evaluation of 3 Mix and Other Mixin non-instrumental endodontic treatment of necrosed primary teeth. Journal of Oral Biology and Craniofacial Research, 2014; 4: 114-9.

17. Trairatvorakul C, Detsomboonrat P. Success rates of a mixture of ciprofloxacin, metronidazole, and minocycline antibiotics used in the non-instrumentation endodontic treatment of mandibular primary molars with carious pulpal involvement. Int J Paediatr Dent, 2012; 22(3): 217-27.

18. K Ramar, J Mungara. Clinical and radiographic evaluation of pulpectomies using three root canal filling materials: An in-vivo study,2010; 28: 25-29. 